\title{
Childhood vaccination against seasonal influenza - is there a risk of undesirable outcomes?
}

\author{
Marc Baguelin ${ }^{1,2^{*}}$ and W. John Edmunds ${ }^{2}$ \\ Please see related article: https://bmcmedicine.biomedcentral.com/articles/10.1186/s12916-019-1471-x
}

\section{Background}

Despite vaccination programmes being in place for decades, the burden associated with influenza remains high, particularly at the ends of the age spectrum. Hospitalisation rates are highest in young children [1], increasing again in the elderly, where most of the deaths associated with influenza are concentrated [2]. As with other vaccines, two approaches exist - the first strategy targets the groups most likely to develop complications following infection, whereas the second targets the transmitters to offer direct and indirect protection to the population through reduced transmission in the community.

\section{Approaches to influenza control}

Historically, influenza control has focused on offering direct protection to individuals most at risk, including those with predisposing conditions, such as chronic respiratory diseases or the immunocompromised, and the elderly. However, given the remaining burden, many national programmes are exploring the extension of coverage to other groups. In the US, vaccination was extended to a universal programme based on the high hospitalisation burden in young children and, in the UK, a childhood vaccination programme has been implemented following the licencing of a liveattenuated influenza vaccine for younger age groups.

Influenza seasons are characterised by their variability, with the three families of strains circulating every year at different intensities. Similarly, the efficacy of influenza vaccines also fluctuates year on year as a result of the evolution of the circulating strains [3]. Assessing the impact of any intervention has to account for this

\footnotetext{
* Correspondence: m.baguelin@imperial.ac.uk

${ }^{1}$ MRC Centre for Global Infectious Disease Analysis, School of Public Health, Imperial College London, London, UK

${ }^{2}$ Department of Infectious Disease Epidemiology, Faculty of Epidemiology and Population Health, London School of Hygiene and Tropical Medicine, London, UK
}

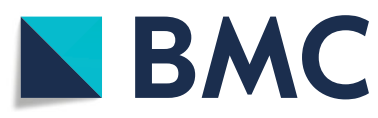

(C) The Author(s). 2020 Open Access This article is distributed under the terms of the Creative Commons Attribution 4.0 International License (http://creativecommons.org/licenses/by/4.0/), which permits unrestricted use, distribution, and

reproduction in any medium, provided you give appropriate credit to the original author(s) and the source, provide a link to the Creative Commons license, and indicate if changes were made. The Creative Commons Public Domain Dedication waiver (http://creativecommons.org/publicdomain/zero/1.0/) applies to the data made available in this article, unless otherwise stated. uncertain background - a policy might appear very costeffective during a high intensity season whereas not so in a quiet one or in a year when there is a poor fit between the vaccine and the predominant strain.

In their recent article, de Boer et al. [4] assess the potential dynamics resulting from repeatedly vaccinating children against the flu season after season. For this, they use an age-structured susceptible-infected-recovered (SIR) model in which immunity is carried over from one season to another but may wane over time (at a more rapid rate for vaccine-derived immunity) [5]. They derive scenarios of the likely impact of replacing some of the immunity previously acquired through infections by that acquired through vaccination. Their results suggest that, in such a setting, vaccinating children is likely to be a very cost-effective way of tackling influenza - at an estimated $€ 3944$ per quality-adjusted life year (QALY) gained, the policy is way below the Dutch national threshold of $€ 20,000$ per QALY gained.

Other authors have similarly found that childhood vaccination may be cost-effective in high-income settings $[6,7]$. However, what distinguishes de Boer et al.'s [4] analysis is suggesting the benefits of influenza vaccination of children might come at the price of more yearon-year variability in outbreak size. Indeed, they suggest that in some years we would experience larger epidemics than would have been expected without childhood vaccination; this is vital as one of the motivations for targeting children through an influenza programme is to reduce the incidence during the winter period, thus reducing winter pressures on health systems. In contrast to a comparable study [7], De Boer et al. [4] also predict that around $90 \%$ of the QALYs gained from the paediatric vaccination programme would arise from preventing deaths, with the remaining occurring through the prevention of illness. As most fatalities occur in the elderly, then most of the benefits of the programme fall to the 
older age groups, with the programme deemed not costeffective if considering the benefits to children alone. These findings do not impact on the economic analysis, as all relevant benefits and costs should be included; however, they could have important equity and health messaging implications if the main beneficiaries of the programme are not those that are receiving the vaccine.

All models are simplifications of complex real-life systems. The art in building a model is to eliminate unnecessary complications, yet models can be criticised for over-simplifying. In the case of transmission models used to inform on influenza vaccination policies, there has been a tendency to make crude assumptions about natural and vaccine-induced immunity. For example, evidence is mounting of an individual's antibody responses being skewed towards the first strains encountered during their lifetime [8] and of a decrease in antibody response following several infections. Translating and transposing measures of vaccine efficacy as measured in the field into models is also difficult as protection can be against acquiring infection, transmission or symptoms; these varying levels of protection will have different effects on the dynamics and therefore, potentially, on the cost-effectiveness of different policies. To date, these more realistic assumptions about immunity have not been adopted into economic analyses, including that by de Boer et al. [4] - it remains to be seen how important they may be.

\section{Looking to the future}

During the first years following the introduction of paediatric influenza vaccination, the UK immediately piloted the new programme in some regions while others had a more progressive introduction. This patchy and gradual introduction lends itself to analysis as a natural experiment, yet the results are difficult to interpret, particularly when added to the temporal variability in influenza seasonal burden and vaccine effectiveness. At present, findings are not clear cut and appear to vary between clinical endpoints. For instance, data suggests that the programme might result in indirect protection of unvaccinated age groups, with a reduction of physician consultations for influenza-like illness in those aged over 17 years in the pilot areas; however, the same studies suggest that there has been no apparent positive impact on excess mortality $[9,10]$.

\section{Conclusions}

Making sense of this complex picture will take time. This process may well be helped by fitting a model to the data in an evidence synthesis approach or by combining the information from the different pilot seasons with a model to help quantify the impact of the programme on different clinical endpoints. If de Boer et al. [4] are right, then we might eventually see a worse epidemic in areas that have had the highest coverage for the longest time - thankfully, to date, nothing of the sort has been observed and the risk remains theoretical.

\section{Acknowledgements}

Not applicable.

\section{Authors' contributions}

Both authors drafted the manuscript. Both authors read and approved the final manuscript.

\section{Authors' information}

Dr. Marc Baguelin is an associate professor at the London School of Hygiene and Tropical Medicine and a lecturer at Imperial College London, he developed the model that led to the introduction of the childhood immunisation programme against seasonal influenza in the UK. John Edmunds is professor of infectious disease modelling at the London School of Hygiene and Tropical Medicine and has worked on influenza and vaccine-preventable disease policy for many years.

\section{Funding}

The authors thank the MRC Centre for Global Infectious Disease Analysis (grant MR/R015600/1) and the UK National Institute for Health Research Health Protection Research Unit (NIHR HPRU) in Modelling Methodology (Imperial College London) and Immunisation (London School of Hygiene and Tropical Medicine) in partnership with Public Health England (PHE) (grant HPRU-2012-10080) for funding. The views expressed are those of the authors and not necessarily those of the MRC, the UK National Health Service, the UK National Institute for Health Research, the UK Medical Research Council, the UK Department of Health, or Public Health England.

\section{Availability of data and materials \\ Not applicable.}

Ethics approval and consent to participate

Not applicable.

\section{Consent for publication}

Not applicable.

\section{Competing interests}

The authors declare that they have no competing interests.

Received: 23 January 2020 Accepted: 3 February 2020

Published online: 12 March 2020

\section{References}

1. Yokomichi H, Mochizuki M, Lee JJ, Kojima R, Yokoyama T, Yamagata Z. Incidence of hospitalisation for severe complications of influenza virus infection in Japanese patients between 2012 and 2016: a cross-sectional study using routinely collected administrative data. BMJ Open. 2019;9: e024687. https://doi.org/10.1136/bmjopen-2018-024687.

2. Cromer D, van Hoek AJ, Jit M, Edmunds WJ, Fleming D, Miller E. The burden of influenza in England by age and clinical risk group: a statistical analysis to inform vaccine policy. J Inf Secur. 2014;68(4):363-71. https://doi.org/10.1016/ j.jinf.2013.11.013.

3. Belongia EA, Simpson MD, King JP, Sundaram ME, Kelley NS, Osterholm MT, et al. Variable influenza vaccine effectiveness by subtype: a systematic review and meta-analysis of test-negative design studies. Lancet Infect Dis. 2016;16:942-51. https://doi.org/10.1016/S1473-3099(16)00129-8.

4. de Boer PT, Backer JA, van Hoek AJ, Wallinga J. Vaccinating children against influenza: overall cost-effective with potential for undesirable outcomes. BMC Med. 2020;18:11. https://doi.org/10.1186/s12916-019-1471-x.

5. Backer JA, van Boven $M$, van der Hoek W, Wallinga J. Vaccinating children against influenza increases variability in epidemic size. Epidemics. 2019;26: 95-103. https://doi.org/10.1016/j.epidem.2018.10.003.

6. Pitman RJ, Nagy LD, Sculpher MJ. Cost-effectiveness of childhood influenza vaccination in England and Wales: results from a dynamic transmission model. Vaccine. 2013;31:927-42. https://doi.org/10.1016/J. VACCINE.2012.12.010. 
7. Baguelin M, Camacho A, Flasche S, Edmunds WJ. Extending the elderly- and risk-group programme of vaccination against seasonal influenza in England and Wales: a cost-effectiveness study. BMC Med. 2015;13:236.

8. Gostic KM, Ambrose M, Worobey M, Lloyd-Smith JO. Potent protection against H5N1 and H7N9 influenza via childhood hemagglutinin imprinting. Science. 2016;354:722-6.

9. Pebody RG, Green HK, Andrews N, Zhao H, Boddington N, Bawa Z, et al. Uptake and impact of a new live attenuated influenza vaccine programme in England: early results of a pilot in primary school-age children, 2013/14 influenza season. Euro Surveill. 2014;19:20823.

10. Pebody RG, Green HK, Andrews N, Boddington NL, Zhao H, Yonova I, et al. Uptake and impact of vaccinating school age children against influenza during a season with circulation of drifted influenza a and B strains, England, 2014/15. Euro Surveill. 2015;20:30029. https://doi.org/10.2807/15607917.ES.2015.20.39.30029

\section{Publisher's Note}

Springer Nature remains neutral with regard to jurisdictional claims in published maps and institutional affiliations.

Ready to submit your research? Choose BMC and benefit from:

- fast, convenient online submission

- thorough peer review by experienced researchers in your field

- rapid publication on acceptance

- support for research data, including large and complex data types

- gold Open Access which fosters wider collaboration and increased citations

- maximum visibility for your research: over $100 \mathrm{M}$ website views per year

At BMC, research is always in progress.

Learn more biomedcentral.com/submissions 